\title{
Impact of shift work on the cortisol awakening response and stress: a longitudinal study in female shifting monthly nurses
}

Wen-Pei Chang ( $\nabla 10479 @ s . t m u . e d u . t w)$

Taipei Medical University https://orcid.org/0000-0002-4906-2136

Hsiu-Ju Jen

Taipei Medical University

\section{Research}

Keywords: Cortisol awakening response, Stress, Female, Monthly shift, Nurses

Posted Date: January 6th, 2020

DOI: https://doi.org/10.21203/rs.2.20101/v1

License: (c) (i) This work is licensed under a Creative Commons Attribution 4.0 International License.

Read Full License 


\section{Abstract}

Background: Although the majority of shift nurses are female, there is still an expectation that they fulfil the traditional role of women in the family, often conflicting with shift work, increases stress, and affects cortisol secretion patterns. This study was to understand the changes in the cortisol awakening response (CAR) and work stress in nursing personnel working in different shifts.

Methods: 41 female shift nurses were recruited that fit criteria using purposive sampling. We obtained personal information, administered the Taiwan Nurse Stress Checklist (NSC), and the nurses themselves collected saliva samples upon waking and 30 minutes after waking for three consecutive days at home. We then analyzed the data obtained using a hierarchical linear model.

Results: The results revealed that night-shift nurses derived significantly more stress from an inability to complete personal tasks than did day-shift nurses $(B=4.39, p<.001)$ or evening-shift nurses $(B=3.95, p$ $<.001)$. Night-shift nurses also exhibited significantly lower $C A R i$ than did day-shift nurses $(B=-3.41, p<$ .001 ) or evening-shift nurses $(B=-2.92, p<.01$ ) as well as significantly lower cortisol levels 30 minutes after waking than did day-shift nurses $(B=-3.88, p<.001)$ or evening-shift nurses $(B=-3.31, p<.01)$.

Conclusions: This study indicate that female night-shift nurses displayed the lowest CARi and cortisol levels 30 minutes after waking and are more negatively affected by being unable to complete personal tasks.

\section{Background}

The work environments and duties of nursing personnel are extremely complex. They must monitor the mental and physical conditions of their patients, meet the needs of the family members of their patients, and communicate with their supervisors, co-workers, and other medical personnel. In addition to their work environments being full of noise and communicable diseases, they must also cope with heavy workloads and time stress. These are all sources of stress in nursing [1]. Moreover, women are still expected to serve the traditional roles in their families, for example, by cooking, doing housework, and caring for children and elders. This career model in which women must meet the demands of both family and work thus places even more stress on female nursing personnel [2].

Researchers have identified that shift work itself is a stressor. Nurses working shifts must continuously adjust to changes in the external environment, which means ever-changing lifestyles and psychological stress [3]. Altering the time of waking can have a profound impact on cortisol levels, which are a crucial activity index of neuroendocrine systems faced with stress [4]. The hypothalamus-pituitary-adrenal (HPA) axis is extremely meaningful in regard to responses to physiological or psychological stimuli of the human body. The balanced operations of this endocrine system rely on a regular sleep schedule, the keeping of which in turn relies on the normal fluctuations in cortisol levels during the last 24 hours. Cortisol levels of an individual are highest upon waking in the morning and lowest at night during sleep. Only in this way can a regular sleep schedule be maintained [5-7]. Moreover, cortisol secretion is a 
physiological self-defense mechanism to cope with stress [8]. HPA axis stimulation has a stronger impact on hormones when it takes place in the morning than when it happens in the evening $[5,9]$. Thus, sleep schedules are closely associated with cortisol levels. Vangilova et al. also indicted that working at night results in lower cortisol levels in the morning after, but after the fifth night of working at night, cortisol levels will become the inverse of the original day-night cycle [10].

The cortisol awakening response (CAR) plays a crucial role in human HPA axis activation during the awakening process. It is an important indicator of HPA axis activity and is highly associated with the arousal system in the brainstem [11]. CAR is widely accepted as being fairly stable; cortisol levels in the human body swiftly rise upon wakening and peaks 30 minutes later. At present, it is known to be associated with energy increase or anticipated stress, which elevates average cortisol levels by $50-100 \%$. Such levels persist for at least an hour and then slowly decline. Subsequently, secretions decline from day to night and maintain periodic changes $[12,13]$.

Although an increasing number of studies are using CAR to detect adrenocortical activity, most studies on nursing personnel working shifts examined stress and CAR on a single level. No relevant studies have used multilevel models so far. The hierarchical linear model (HLM) is currently one of the most suitable statistical methods for multilevel data analysis. The model regards observation time points as the first level and the basic attributes of nursing personnel as the second level while examining the relationships among variables. We thus performed a longitudinal analysis on the panel data collected and used the HLM growth model to (1) understand the changes in CAR and work stress in nursing personnel working in different shifts, (2) determine the influence of specific attributes of female nurses (age, religion, marital status, educational background, and years of service) on CAR and work stress, and (3) examine the relationship between CAR and stress. Figure 1 displays the conceptual framework of this study.

\section{Methods}

\section{Study design}

This study investigated nurses working shifts at a teaching hospital in Northern Taiwan. This study investigated nurses working shifts at a teaching hospital in Northern Taiwan. A portion of the data collection has already been published [14]. We recruited 41 nurses from January of 2017 to January of 2018 who were working monthly rotating shifts between the ages of 20 and 45 with more than one year of experience as a clinical nurse. Nurses who were pregnant or were using contraceptives or hormone medication were excluded.

Monthly rotating shifts were defined as the three-shift system in which working hours are divided into day shift (08:00-16:00), evening shift (16:00-24:00), and night shift (00:00-08:00). Nurses change shifts every month, which is classified as slow rotation [15].

We adopted a prospective, longitudinal research design with purposive sampling. Repeated measurements were performed on shift nurses at a teaching hospital in Northern Taiwan to determine the 
influence of different shifts and work stress on CAR. Wirth et al. found that individuals who sometimes work night shift or evening shift wake up with lower CAR values than those who permanently work day shift [16]. The difference between these two groups of individuals is greatest on the 5th day after a shift change and gradually decreases from the 7th day to the 14th day after a shift change. To eliminate the influence of shift changes, we conducted the first structured interviews 14 days after shift changes. Subsequent structured interviews were then conducted on the 14th day of the next month and the 14th day of the following month for follow-up data collection. Our procedure follows nurses across three consecutive shift changes over three months that cover day, evening, and night shifts.

\section{Research tools}

The measurement tools included a basic information sheet, the Taiwan Nurse Stress Checklist (NSC), and a radioimmunoassay $(\mathrm{RI} A)$ :

Basic information sheet: This included information on the age, religion, marital status, educational background, and years of service of the nurses.

Taiwan Nurse Stress Checklist (NSC): The Taiwan NSC is based on the scale developed by Benoliel to gauge the work stress that a nurse has experienced during the week prior [17]. Each question item was measured using a nine-point Likert scale ranging from 0 to 8 points, with a higher score indicating greater stress. The scale was divided into five domains: personal reactions, personal concerns, work concerns, role competence, and work completion concerns. Internal consistency ranged from 0.80 to 0.91 . Tsai and Chen revised the scale for application in Taiwan [18]. The checklist includes four aspects of stress containing a total of 43 question items. Personal reactions contain 16 question items with regard to the negative physical and mental reactions of the nurses toward their work. Work concerns contain 13 question items regarding issues in their communication with patients, patient family members, or doctors during work as well as their personal disappointed expectations of the professional or healthcare system. Work competence contains 11 question items concerning self-satisfaction with work completion and personal professional abilities. Inability to complete personal tasks contain 3 question items regarding the interactions between the nurses and their living environment, including unfinished chores, such as laundry or grocery shopping. The Cronbach's a of each aspect was greater than 0.84 .

Radioimmunoassay (RIA): In this study, we used RIA to measure the amount of cortisol in the saliva of the participants. Measuring the physiological indicators of saliva is a noninvasive approach to measure stress which is simple and cost-effective. At present, while it is known that cortisol levels in saliva is a tenth of those in serum, the variations in the two are the same, so changes in cortisol levels in saliva accurately reflect changes in serum cortisol levels. A single saliva sample presents inadequate stability in cortisol results, so saliva samples were collected for three consecutive days at two different times to measure CAR variations, one immediately upon waking and the other at 30 minutes after waking $[12,19]$. Many studies use the same two timepoints to measure CAR [20,21]. CAR plays a crucial role in increasing the energy expected to be necessary for the human body to cope with a day's work [22]. CARi (the 
increase in cortisol following waking) is an extremely valid and standardized method of measuring HPA axis responsiveness and estimates the average increase in cortisol levels during the first 30 minutes after waking [23]. For the sake of stability in the cortisol saliva sample data, the participants were asked not to eat within the 30 minutes before taking their sample and collect more than $3 \mathrm{ml}$ of saliva. All saliva samples had to be frozen for storage after being taken. Prior to analysis, the samples were stored in a freezer at $-20^{\circ} \mathrm{C}$. For analysis, the samples were thawed, mixed, and then centrifuged to remove particulate matter. System precision tests on the cortisol analysis system were performed five times as suggested by Wilson and Miles [24]. The intra-assay CV \% and inter-assay CV \% of the cortisol RIA analysis system were $0.96 \%$ and $12.09 \%$, respectively, and the detection limit was $1.66 \mathrm{nmol} / \mathrm{I}$.

\section{Statistical Analyses}

We first employed SPSS for Windows 21.0 (SPSS, Chicago, IL, USA) to obtain the descriptive statistics and subsequently performed an ANOVA. Using HLM 6.03 (SSI, 2010), we then conducted HLM analysis on the panel data obtained. In model selection, we first used the null model to derive within group variance ( $\sigma 2)$ and between group variance ( $(00)$. According to Cohen, an intraclass correlation coefficient (ICC), which equals ( $(00) /(\tau 00+\sigma 2)$, greater than $5.9 \%$ (moderate effects) indicates significant variance in the result variables of individual participants [25]. Using a random coefficients regression model and an intercepts-as-outcomes model, we then determined whether the basic attributes and shifts of the nurses exert significant influence on stress and CAR.

\section{Results}

\section{Basic attributes of female shift nurses}

The mean age of the participating nurses was 25.0 (range = 21.0-40.0). In terms of religion, the largest group $(48.8 \%)$ was not religious. The vast majority of the participants $(95.1 \%)$ were either single or divorced. Most $(70.7 \%)$ had a bachelor's degree or higher. With regard to years of service, the largest group (43.9\%) have worked for $1-3$ years (Table 1 ). 
Table 1

Basic information of shift nurses $(\mathrm{N}=41)$

\begin{tabular}{|lll|}
\hline Characteristics & $\mathbf{n}$ & Value (\%) \\
\hline Religion & & \\
None & 20 & 48.8 \\
Buddhism / Taoism & 17 & 41.5 \\
Christianity / Catholicism & 4 & 9.8 \\
\hline Marital status & & \\
\hline Married & 2 & 4.9 \\
\hline Single or divorced & 39 & 95.1 \\
\hline Educational background & & \\
\hline Junior college & 12 & 29.3 \\
\hline University or above & 29 & 70.7 \\
\hline Years of service & & \\
\hline 1-3 years & 18 & 43.9 \\
\hline 3-5 years & 9 & 22.0 \\
\hline 5-7 years & 8 & 19.5 \\
\hline Over 7 years & 6 & 14.6 \\
\hline Age (years) & Median & Range \\
\hline
\end{tabular}

\section{CAR differences among shifts}

The CARi values of the nurses in morning, evening, and night shifts were $8.04 \pm 4.26,7.49 \pm 4.28$, and $4.83 \pm 3.60$. An ANOVA revealed CARi differences among different shifts $(F(2,120)=7.13, p=.001)$. Figure 2 presents the CARi trends in the nurses working different shifts.

Level-1 (intraindividual) variance of the CARi, cortisol levels upon waking, and cortisol levels 30 minutes after waking was $12.42,4.91$, and 15.75 , respectively, whereas Level-2 (interindividual) variance was 5.87 $(p<.05), 5.71(p<.001)$, and $15.45(p<.001)$, respectively. For the different shifts, the ICCs were 0.3208, 0.5379 , and 0.4952 , respectively, all higher than the threshold of $13.8 \%$ for high correlation ${ }^{25}$ ). This means that the interclass differences among the nurses of different shifts in CARi, cortisol levels upon waking, and cortisol levels 30 minutes after waking cannot be ignored and that cross-level analysis is necessary 
[26]. Thus, a respective $32.08 \%, 53.79 \%$, and $49.52 \%$ of the total variance in CARi, cortisol levels upon waking, and cortisol levels 30 minutes after waking are caused by interindividual variance.

As shown in Table 2, significant differences existed between the CARi of night-shift nurses and that of day-shift nurses $(B=-3.41, p<.001)$, and between the CARi of night-shift nurses and evening-shift nurses $(B=-2.92, p<.01)$, indicating that night-shift nurses exhibited significantly lower CARi than did day-shift nurses or evening-shift nurses. The other variables did not have a significant impact on CARi and no variables were shown to have a significant impact on cortisol levels upon waking, whereas significant differences existed for cortisol levels 30 minutes after waking between night-shift nurses and day-shift nurses $(B=-3.88, p<.001)$, and between night-shift nurses and evening-shift nurses $(B=-3.31, p<.01)$, indicating that night-shift nurses exhibited significantly lower cortisol levels 30 minutes after waking than did day-shift nurses or evening-shift nurses. The other variables did not have a significant impact on cortisol levels 30 minutes after waking. 
Table 2

Influence of study variables on CAR $(\mathrm{N}=41)$

\section{Independent variables}

CARi Cortisol levels upon waking

Cortisol levels $\mathbf{3 0}$ minutes after waking

Fixed effect

Level 1

Intercept

11.02

3.96

$15.16^{*}$

Shift

Evening vs day

$-0.50$

$-0.06$

$-0.56$

Night vs day

$-3.41^{\star *}$

$-0.52$

$-3.88^{* *}$

Night vs evening

$-2.92^{*}$

$-0.45$

$-3.31 * \star$

Work stress

Personal reactions

$-0.02$

0.01

$-0.01$

Work concerns

$-0.01$

$-0.01$

$-0.02$

Work competence

0.01

$-0.03$

$-0.02$

Inability to complete personal tasks

0.07

0.09

0.15

Level 2

Age

$-0.18$

$-0.01$

$-0.19$

Religion

Buddhism Taoism $^{\text {a }}$

0.38

0.53

0.93

Christianity / Catholicism ${ }^{\text {a }}$

0.24

$-0.67$

$-0.42$

Marital status (Single or divorced) ${ }^{b}$

0.99

3.22

4.22

Educational background (University or above) ${ }^{c}$

1.19

0.53

1.74

${ }^{*} \mathrm{p}<.05 ; * \star \mathrm{p}<.01 ; * * \star \mathrm{p}<.001$

${ }^{\text {a }}$ Religion as the reference group

${ }^{b}$ Married as the reference group

c Junior college as the reference group

d $1-3$ years of service as the reference group 


\begin{tabular}{|c|c|c|c|}
\hline Independent variables & CARi & $\begin{array}{l}\text { Cortisol levels } \\
\text { upon waking }\end{array}$ & $\begin{array}{l}\text { Cortisol levels } 30 \\
\text { minutes after waking }\end{array}$ \\
\hline \multicolumn{4}{|l|}{ Years of service } \\
\hline $3-5$ years $^{d}$ & -0.57 & 0.77 & 0.20 \\
\hline $5-7$ years $^{d}$ & 0.14 & 0.44 & 0.56 \\
\hline Over 7 years $^{d}$ & 0.33 & -0.09 & 0.19 \\
\hline \multicolumn{4}{|l|}{ Random effect } \\
\hline Level 2 (Variance component between groups) & $8.84 \star \star$ & $6.03^{\star *}$ & $18.99 * \star$ \\
\hline Level 1 (Variance component within group) & $9.99 \star \star \star$ & $5.03^{\star \star \star}$ & $13.11^{\star \star \star}$ \\
\hline \multicolumn{4}{|l|}{${ }^{\star} \mathrm{p}<.05 ; * \star \mathrm{p}<.01 ; * \star \star \mathrm{p}<.001$} \\
\hline \multicolumn{4}{|l|}{ a Religion as the reference group } \\
\hline \multicolumn{4}{|l|}{${ }^{\mathrm{b}}$ Married as the reference group } \\
\hline \multicolumn{4}{|l|}{${ }^{\mathrm{c}}$ Junior college as the reference group } \\
\hline
\end{tabular}

\section{Work stress differences among shifts}

The work stress scores of the nurses in morning, evening, and night shifts were 113.41 (SD = 64.35), 119.17(SD = 58.94), and 125.46(SD = 57.72), respectively. An ANOVA revealed no significant differences in work stress among the nurses working different shifts.

Level-1 (intraindividual) variance of the work stress of the female shift nurses was 843.93, while Level-2 (interindividual) variance was $2815.89(p<.001)$. The ICC was 0.7694 , indicating that differences in work stress among the nurses of different shifts cannot be ignored and that $76.94 \%$ of the total variance is caused by interindividual variance.

As can be seen in Table 3, the regression coefficients of all of the variables did not reach the level of significance in personal reaction and overall work stress. For work concerns, only age $(B=-3.25, p<.05)$ reached the level of significance, indicating that older nurses derived less stress from work concerns. With respect to the inability to complete personal tasks, significant differences existed between night-shift nurses and day-shift nurses $(B=4.39, p<.001)$, and between night-shift nurses and evening-shift nurses $(B=3.95, p<.001)$, thus night-shift nurses derived significantly more stress from the inability to complete personal tasks than did day-shift nurses or evening-shift nurses. 
Table 3

Influence of research variables on work stress of shift nurses $(N=41)$

\begin{tabular}{|c|c|c|c|c|c|}
\hline Independent variables & $\begin{array}{l}\text { Personal } \\
\text { reaction }\end{array}$ & $\begin{array}{l}\text { Work } \\
\text { concerns }\end{array}$ & $\begin{array}{l}\text { Work } \\
\text { competence }\end{array}$ & $\begin{array}{l}\text { Inability to } \\
\text { complete } \\
\text { personal tasks }\end{array}$ & $\begin{array}{l}\text { NSCG } \\
\text { total score }\end{array}$ \\
\hline \multicolumn{6}{|l|}{ Fixed effect } \\
\hline \multicolumn{6}{|l|}{ Level 1} \\
\hline Intercept & $63.03 *$ & $87.49 \star \star$ & $63.37 *$ & 7.18 & $221.79 \star \star$ \\
\hline \multicolumn{6}{|l|}{ Shift } \\
\hline Evening vs day & 2.91 & 3.55 & -1.30 & 0.44 & 5.61 \\
\hline Night vs day & 5.25 & 1.95 & 0.31 & $4.39 \star \star \star$ & 11.91 \\
\hline Night vs evening & 2.34 & -1.61 & 1.61 & $3.95^{\star \star \star}$ & 6.29 \\
\hline \multicolumn{6}{|l|}{ Level 2} \\
\hline Age & -1.55 & $-3.25^{\star}$ & -1.29 & -0.04 & -6.17 \\
\hline \multicolumn{6}{|l|}{ Religion } \\
\hline Buddhism / Taoism ${ }^{\text {a }}$ & 8.86 & 6.93 & 4.53 & 1.57 & 21.88 \\
\hline $\begin{array}{l}\text { Christianity / } \\
\text { Catholicism }^{a}\end{array}$ & -4.44 & -10.49 & -6.59 & 0.90 & -20.70 \\
\hline $\begin{array}{l}\text { Marital status (Single or } \\
\text { divorced) } b\end{array}$ & 7.63 & 12.66 & 0.98 & 0.52 & 21.98 \\
\hline $\begin{array}{l}\text { Educational background } \\
\text { (University or above) }^{c}\end{array}$ & 9.95 & 6.10 & 1.31 & 1.70 & 19.16 \\
\hline \multicolumn{6}{|l|}{ Years of service } \\
\hline $3-5$ years $^{d}$ & 8.52 & 8.13 & 2.55 & 0.15 & 19.47 \\
\hline $5-7$ years $^{d}$ & 6.97 & 17.17 & -0.84 & 0.23 & 23.72 \\
\hline \multicolumn{6}{|c|}{${ }^{*} \mathrm{p}<.05 ; * * \mathrm{p}<.01 ; * * \star p<.001$} \\
\hline \multicolumn{6}{|c|}{${ }^{\text {a }}$ Religion as the reference group } \\
\hline \multicolumn{6}{|c|}{${ }^{b}$ Married as the reference group } \\
\hline \multicolumn{6}{|c|}{ c Junior college as the reference group } \\
\hline
\end{tabular}




\begin{tabular}{|c|c|c|c|c|c|}
\hline Independent variables & $\begin{array}{l}\text { Personal } \\
\text { reaction }\end{array}$ & $\begin{array}{l}\text { Work } \\
\text { concerns }\end{array}$ & $\begin{array}{l}\text { Work } \\
\text { competence }\end{array}$ & $\begin{array}{l}\text { Inability to } \\
\text { complete } \\
\text { personal tasks }\end{array}$ & $\begin{array}{l}\text { NSCG } \\
\text { total score }\end{array}$ \\
\hline Over 7 years $^{d}$ & -7.94 & 28.39 & 4.34 & -2.96 & 22.35 \\
\hline \multicolumn{6}{|l|}{ Random effect } \\
\hline $\begin{array}{l}\text { Level } 2 \text { (Variance } \\
\text { component between } \\
\text { groups) }\end{array}$ & $571.72^{\star \star \star}$ & $345.46 * \star \star$ & $227.96 * \star \star$ & $17.97 \star \star$ & $2930.95^{\star \star \star}$ \\
\hline $\begin{array}{l}\text { Level } 1 \text { (Variance } \\
\text { component within } \\
\text { group) }\end{array}$ & $180.57 * \star \star$ & $88.09 * \star \star$ & 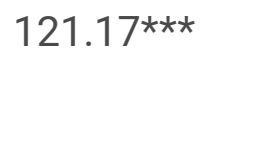 & $17.16^{\star \star \star}$ & $821.90 * \star \star$ \\
\hline \multicolumn{6}{|c|}{${ }^{*} \mathrm{p}<.05 ; * \star \mathrm{p}<.01 ; * \star \star \mathrm{p}<.001$} \\
\hline \multicolumn{6}{|c|}{${ }^{a}$ Religion as the reference group } \\
\hline \multicolumn{6}{|c|}{${ }^{b}$ Married as the reference group } \\
\hline \multicolumn{6}{|c|}{${ }^{\mathrm{C}}$ Junior college as the reference group } \\
\hline d $1-3$ years of service $a$ & reference & oup & & & \\
\hline
\end{tabular}

\section{Influence of work stress on CAR}

An ANOVA of the stress from personal reactions, work concerns, work competence, and inability to complete personal tasks for nurses working the three different shifts presented no significant differences. With the shift and other personal attributes controlled, the four aspects of work stress also showed no significant differences in their influence on the CARi, cortisol levels upon waking, or cortisol levels 30 minutes after waking of female shift nurses (Table 3).

\section{Discussion}

Waking time and stress are both considered factors influencing CAR, but the correlations with these factors are still unclear. This study is the first to adopt a longitudinal approach to examine the differences among women working different shifts (and waking up at different times) and their correlations with CAR and work stress. The study results revealed that after the personal attributes of the nurses were controlled, night-shift nurses displayed significantly lower CARi and cortisol levels 30 minutes after waking than did day-shift nurses or evening-shift nurses. When religion, marital status, educational background, and years of service were controlled, the results showed that older nurses derived less stress from work concerns. Following the control of the personal attributes of the nurses, the results indicated 
that the night-shift nurses derived more stress from the inability to complete personal tasks than did dayshift nurses or evening-shift nurses.

Cortisol plays a crucial role in regulating the coping mechanism of chronic stress. Shift work exerts influence on multiple physiological, neuroendocrine, and hormonal functions. As a result, CAR is currently considered to be a major index of shift work tolerance [27]. Research has shown that changes in CAR may be the result of increased stress and impaired sleep quality following shift changes; however, controlling for shift factor revealed no significant differences in CAR variations [28]. Many existing studies presented different findings. Federenko et al. found significant increase in CAR in day-shift nurses than in evening-shift or night-shift nurses [29]. Niu et al. further explained that working night shifts conflicts with the sleep schedule of individuals, which causes circadian rhythm disorders, affects sleep quality, induces fatigue, and breaks concentration, thereby reducing work efficiency [30]. Night-shift workers sleep during the day when their cortisol levels are high, which affects the quality and duration of sleep. On average, they sleep 1 to 4 hours less than do day-shift workers sleep during the night, leading to high sleep debts that can cause chronic fatigue. In this study, we performed measurements on the 14th day after shift changes as suggested by Wirth et al. to control the influence of shift change [16]. Interestingly, significant CAR differences still existed. This result supports that CAR is associated with waking time. Individuals who wake in the morning have significantly higher cortisol levels. Those who work evening or night shift (sleep during the day) displayed significantly weaker CAR than those who permanently work day shift (sleep during the night), likely due to the normal circadian rhythm of the latter group [31, 32].

The results of this study also revealed that work stress which shift nurses must cope with varies with age, with older shift nurses feeling less stress from work concerns. Nursing personnel work on the front lines and must have good professional decision-making and execution abilities, be skilled, and have good relationships with patients and other medical personnel, all of which come with increased work experience, because they come into direct contact with patients and their family members. Thus, young nurses must invest more energy in their work and perhaps this causes them to perceive more work stress.

Furthermore, the results of this study also indicated that night-shift nurses suffer more stress from their inability to complete personal tasks. This finding is consistent with the results of other studies. The sleeping period of night-shift nurses is often during the early night and likely when their friends or family have free time, thereby preventing them from spending time with their friends and family. Their shift work causes stress on the best way to utilize their time and hinders them from completing personal tasks. It is difficult for them to find the time for social activities and family life, which are the primary causes of greater stress [33].

Stress the affect CAR magnitudes. Many studies have indicated that CAR is an indicator of stress or emotional disorders. Increased CAR helps the body cope with the stresses in life [7, 34, 35]. A metaanalysis conducted by Chida and Steptoe revealed that CAR is positively correlated with work stress and life stress and negatively correlated with fatigue or burnout [36]. Garcia et al. further pointed out that only 
individuals under a moderate or severe amount of stress perceive themselves as having poorer health and that those with poorer self-perceived health work up with significantly reduced CAR and smaller increases in cortisol levels after waking up [37]. Thus, only moderate and severe amounts of stress and poor self-perceived health alter CAR, which means that a low level of stress does not affect CAR or selfperceived health. This is consistent with the results of our study. After the personal attributes and shifts of the nurses were controlled, we found that the various aspects of work stress did not significantly affect CARi. One explanation for this observation is that the month-long tracking periods of the participants may not be long enough for any significant changes to appear in the various aspects of work stress, so indeed, CARi would not be affected.

\section{Conclusions}

The results of this study indicated that female night-shift nurses displayed the lowest CARi and cortisol levels 30 minutes after waking and were more troubled with the inability to complete personal tasks. Our results imply that monitoring cortisol levels may be necessary to understanding the HPA axis variations in nurses that work shifts. These results also provide hospital managers with a reference when arranging nurse shift schedules. Suitable shift arrangements could reduce the impact of shift work on female nurses and their health.

\section{Limitations}

The number of samples collected in this study was limited and we only investigated female nurses at a single hospital, so the results may not be applicable to other hospitals, other departments, or male nurses. CAR changes were based on only two timepoints: upon waking and 30 minutes after waking. We suggest that future studies include three or more timepoints to measure the changes in CAR which could lead to a more comprehensive analysis.

\section{Declarations}

\section{Ethics approval and consent to participate}

With the approval of the institutional review board (IRB), we explained our objectives and procedure to the research participants and gained their consent. The approval number from the Office of Human Research, Taipei Medical University is N201703064.

\section{Consent for publication}

Not applicable.

\section{Availability of data and materials}


The datasets generated and/or analyzed during the current study are not publicly available due to considerations of data protection.

\section{Competing interests}

The authors have no conflict of interest to disclose.

\section{Funding}

Research reported in this publication was supported by the Taipei Medical University-Shuang Ho Hospital, Ministry of Health and Welfare under award number 106HCP-12.

\section{Authors' contributions}

WPC developed the study conception and methodology; WPC and HJJ collected the data; WPC conducted the cortisol assay; WPC performed the formal analysis statistical analyses; WPC and HJJ critically interpreted the results; HJJ prepared original draft of the manuscript; WPC contributed substantially to the review \& editing.

\section{Acknowledgements}

We thank the anonymous reviewers and editor for their comments.

\section{References}

1. Najimi A, Goudarzi AM, Sharifirad G. Causes of job stress in nurses: A cross-sectional study. Iran J Nurs Midwifery Res. 2012;17:301-5.

2. Gafarov V, Panov D, Gromova E, Gagulin I, Gafarova A. Association of family stress with other psychosocial factors in female population 25-64 years in Russia: WHO program MONICApsychosocial. Eur Psychiatry. 2016;33:

3. Ma CC, Andrew ME, Fekedulegn D, Gu JK, Hartley TA, Charles LE, Violanti JM, Burchfiel CM. Shift work and occupational stress in police officers. Saf Health Work. 2015;6:25-

4. Wichmanna S, Kirschbaumb C, Böhmec C, Petrowskiac K. Cortisol stress response in post-traumatic stress disorder, panic disorder, and major depressive disorder patients. Psychoneuroendocrinology. 2017;83:135-

5. Chung S, Son GH, Kim K. Circadian rhythm of adrenal glucocorticoid: its regulation and clinical implications. Biochim Biophys Acta.2011;1812:581-

6. Herman JP, McKlveen JM, Ghosal S, Kopp B, Wulsin A, Makinson R, Scheimann J, Myers B. Regulation of the hypothalamic-pituitary-adrenocortical stress response. Compr Physiol. 2016;6:603-21.

7. Oster H, Challet E, Ott V, Arvat E, de Kloet ER, Dijk DJ, Lightman S, Vgontzas A, Van Cauter E. The functional and clinical significance of the 24-hour rhythm of circulating glucocorticoids. Endocr Rev. 
2017;38:3-45.

8. Pires da Rocha MC, Figueiredo de Martino MM, Grassi-Kassisse DM, Luiz de Souza A. Stress among nurses: an examination of salivary cortisol levels on work and day off. Revista da Escola de Enfermagem da USP. 2013;47:1194-201.

9. Goncharova ND. Stress responsiveness of the hypothalamic-pituitary-adrenal axis: age-related features of the vasopressinergic regulation. Front Endocrinol. 2013;4:

10. Vangilova K. The effect of shift rotation on variation of cortisol, fatigue and sleeping sound engineers. Ind Health. 2008;46:490-

11. Berger M, Leicht A, Slatcher A, Kraeuter AK, Ketheesan S, Larkins S, Sarnyai Z. Cortisol awakening response and acute stress reactivity in first nations people. Sci Rep. 2017;7:

12. Clow A, Hucklebridge F, Stalder T, Evans $P$, Thorn L. The cortisol awakening response: more than a measure of HPA axis function. Neurosci Biobehav Rev. 2009;35:97-

13. Elder GJ, Ellis JG, Barclay NL, Wetherell MA. Assessing the daily stability of the cortisol awakening response in a controlled environment. BMC Psychol. 2016;4:3-10.

14. Chang WP. Influence of shift type on sleep quality of female nurses working monthly rotating shifts with cortisol awakening response as mediating variable. Chronobiol Int. 2018;35:1503-

15. Wilson JL. The impact of shift patterns on healthcare professionals. J Nurs Manag. 2002;10:211-9.

16. Wirth M, Burch J, Violanti J, Burchfiel C, Fekedulegn D, Andrew M, Zhang H, Miller DB, Hébert JR, Vena JE. Shiftwork duration and the awakening cortisol response among police officers. Chronobiol Int. 2011;28:446-57.

17. Benoliel JQ, McCorkle R, Georgiadou F, Denton T, Spitzer A. Measurement of stress in clinical nursing. Cancer Nurs. 1990;13:221-8.

18. Tsai SL, Chen ML. A test of the reliability and validity of nurse stress checklist. J Nurs Res. 1996;4:355-

19. Seltzer MM, Greenberg JS, Hong J, Smith LE, Almeida DM, Coe C, Stawski RS. Maternal cortisol levels and behavior problems in adolescents and adults with ASD. J Autism Dev Disord. 2010;40:457-69.

20. Filaire E, Ferreira JP, Oliveira M, Massart A. Diurnal patterns of salivary alpha-amylase and cortisol secretion in female adolescent tennis players after 16 weeks of training. Psychoneuroendocrinology. 2013;38:1122-

21. Strahler J, Berndt C, Kirschbaum C, Rohleder N. Aging diurnal rhythms and chronic stress: distinct alteration of diurnal rhythmicity of salivary a-amylase and cortisol. Biol Psychol. 2010;84:248-56.

22. Elder GJ, Wetherell MA, Barclay NL, Ellis JG. The cortisol awakening response- applications and implications for sleep medicine.Sleep Med Rev. 2014;18:215-24.

23. Pruessner JC, Kirschbaum C, Meinlschmid G, Hellhammer DH. Two formulas for computation of the area under the curve represent measures of total hormone concentration versus time-dependent change. Psychoneuroendocrinology. 2003;28: 916-31. 
24. Wilson MA, Miles EM. Radioimmunoassay of insulin. In Abraham GE, ed. Handbook of radioimmunoassay. Marcel Dekker, N.Y., 1978;275-

25. Cohen J. Statistical power analysis for the behavioral sciences (2nd ed.). NJ: Lawrence Earlbaum Associates. 1988.

26. Raudenbush SW, Bryk AS. Hierarchical Linear Models: Applications and Data Analysis Methods (2nd ed.). Thousand Oaks, CA: Sage. 2002.

27. Lammers-van der Holst HM, Kerkhof GA. Individual differences in the cortisol-awakening response during the first two years of shift work: A longitudinal study in novice police officers. Chronobiol Int. 2015;32:1162-7.

28. Williams E, Magid K, Steptoe A. The impact of time of waking and concurrent subjective stress on the cortisol response to awakening. Psychoneuroendocrinology. 2005;30:139-

29. Federenko I, Wust S, Hellhammer DH, Dechoux R, Kumsta R, Kirschbaum C. Free cortisol awakening responses are influenced by awakening time. Psychoneuroendocrinology. 2004;29:174-84.

30. Niu SF, Chung MC, Chen HC, Hegney D, O'Brien A, Chou KR. The effect of shift rotation on mployee cortisol profile, sleep quality, fatigue, and attention level: a systematic review. J Nurs Res. 2011;19:68-

31. Bostock S, Steptoe A. Influences of early shift work on the diurnal cortisol rhythm, mood and sleep: within-subject variation in male airline pilots. Psychoneuroendocrinology. 2013;38:533-41.

32. Griefahn B, Robens S. The cortisol awakening response: a pilot study on the effects of shift work, morningness and sleep duration. 2008;33: 981-8.

33. Costa G. Shift work and health: current problems and preventive actions. Saf Health Work. 2010;1:112-23.

34. Dedovic K, Ngiam J. The cortisol awakening response and major depression: examining the evidence. Neuropsychiatr Dis Treat. 2015;11:1181-

35. Powell DJ, Schlotz W. Daily life stress and the cortisol awakening response: testing the anticipation hypothesis. PLoS One. 2012;7:

36. Chida Y, Steptoe A. Cortisol awakening response and psychosocial factors: a systematic review and meta-analysis. Biol Psychol. 2009;80:265-78.

37. Garcia A, Wilborn K, Mangold D, Garcia AF, Mangold DL. The cortisol awakening response mediates the relationship between acculturative stress and self-reported health in Mexican Americans. Ann Behav Med. 2017;51:787-

\section{Figures}


Variance component between group

Level 2

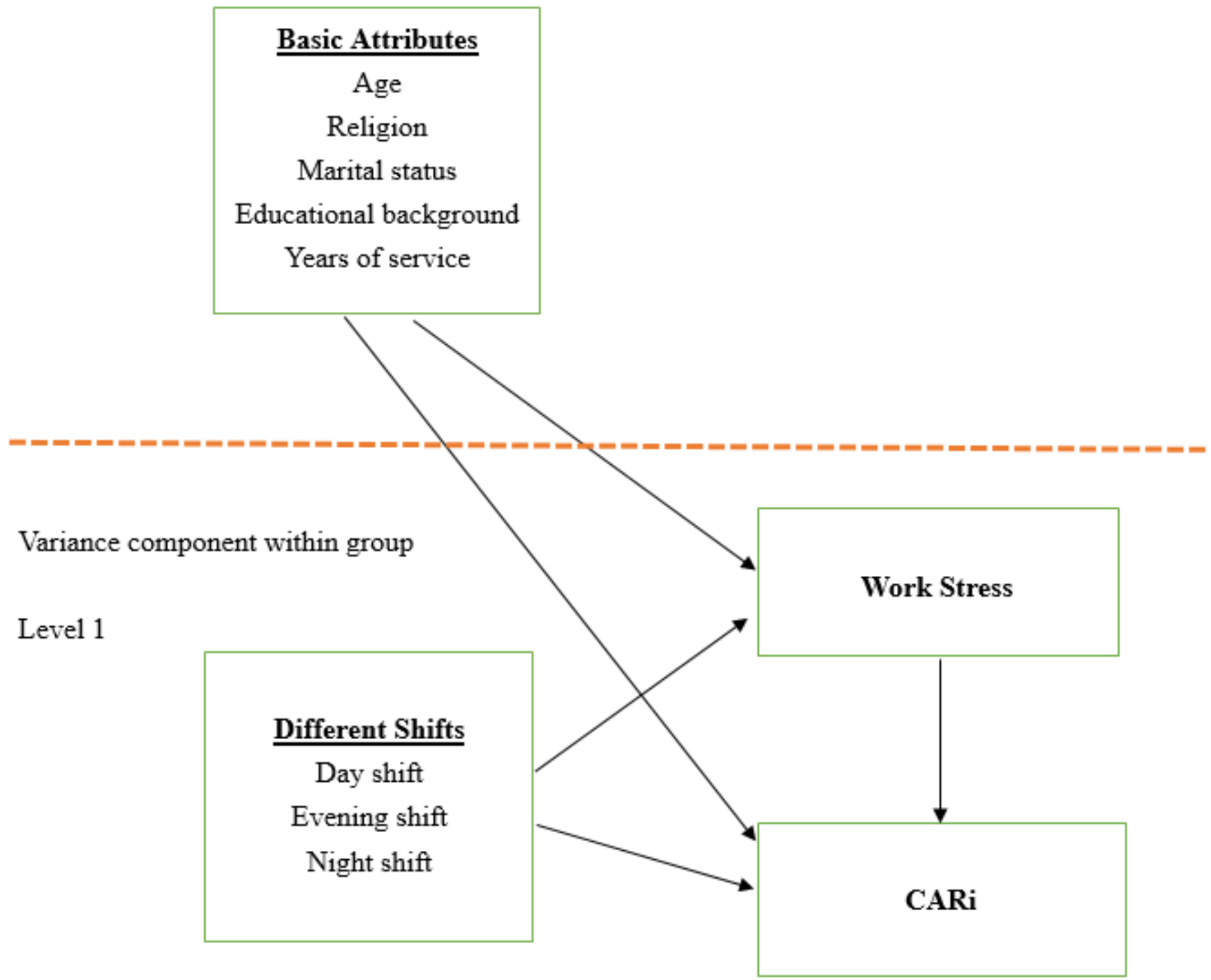

Figure 1

Framework 


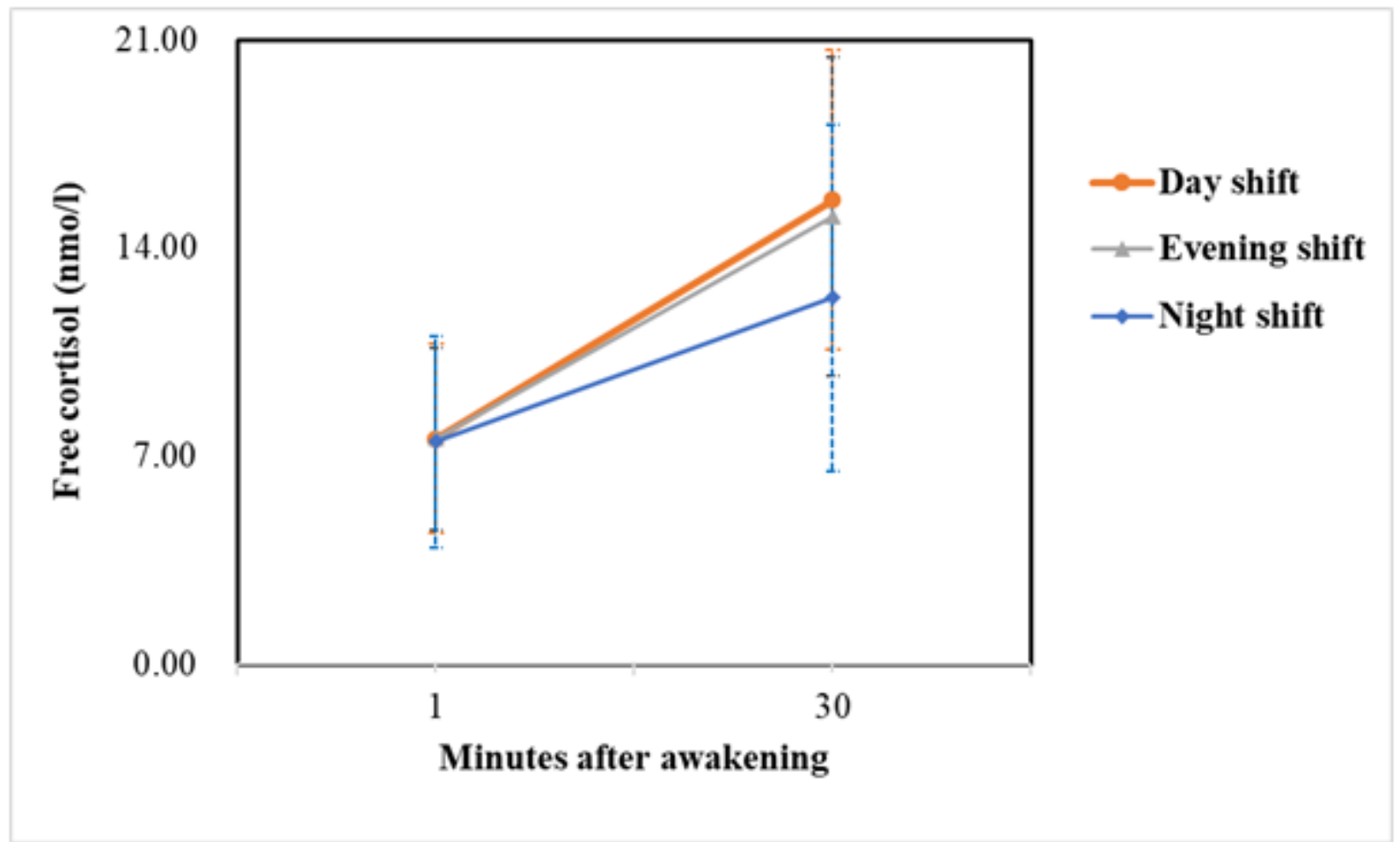

Figure 2

Mean cortisol awakening responses and standard deviation of 41 female nurses working different shifts 